\title{
About the seasonal and fortnightly variabilities of the Mediterranean outflow
}

\author{
C. Millot ${ }^{1}$ and J. Garcia-Lafuente ${ }^{2}$ \\ ${ }^{1}$ Laboratoire d'Océanographie Physique et Biogéochimique (LOPB/COM), UMR6535, \\ CNRS - Université de la Méditerranée, Antenne de Toulon, La Seyne/mer, France \\ ${ }^{2}$ Physical Oceanography Group, University of Málaga (UMA), Málaga, Spain
}

Received: 9 November 2010 - Published in Ocean Sci. Discuss.: 17 December 2010

Revised: 26 April 2011 - Accepted: 4 May 2011 - Published: 15 June 2011

\begin{abstract}
CTD time series from the HYDRO-CHANGES programme and INGRES projects have been collected simultaneously (2004-2008) on the shelf of Morocco and at the sills of Camarinal and Espartel in the strait of Gibraltar. They provide information that supports results recently obtained from the analysis of the two former time series, as well as from a reanalysis of GIBEX CTD profiles (1985-1986). The outflow of Mediterranean Waters, which does not show a clear seasonal variability before entering the strait, strongly mixes within the strait, due mainly to the internal tide, with the seasonally variable inflow of Atlantic Water. The outflow thus gets marked seasonal and fortnightly variabilities within the strait. Furthermore, since the outflowing waters entering the strait display marked spatial heterogeneity and longterm temporal variabilities, accurately predicting the characteristics of the Mediterranean outflow into the North Atlantic Ocean appears almost impossible.
\end{abstract}

\section{Introduction}

Historically, the outflow through the strait of Gibraltar has been considered as composed of only two out of four major Mediterranean Waters (MWs) that are expected to be mixed near $6^{\circ} \mathrm{W}$, thereby producing a rather homogeneous outflow that then splits into veins, due to its cascading along different paths and to different mixing conditions with the Atlantic Water (AW). This concept is neither supported by previous research into the functioning of the Mediterranean Sea nor by recent work concerning the strait itself. In particular,

Correspondence to: C. Millot (ailesetiles@gmail.com) the 1985-1986 GIBEX CTD sections, performed across the strait and sometimes only a few days apart, have been reanalyzed in conjunction with new CTD time series (Fig. 1a, b). The latter have been collected since 2003 with Sea-BirdSBE37-SM CTDs, moored at a few metres above the bottom near the southern sill of Camarinal (point $\mathrm{C}$, at $35^{\circ} 55.2^{\prime} \mathrm{N}-$ $5^{\circ} 45.0^{\prime} \mathrm{W}$ and a nominal depth of $270 \mathrm{~m}$ ) and on the shelf of Morocco (point $\mathrm{M}, 35^{\circ} 52.8^{\prime} \mathrm{N}-5^{\circ} 43.5^{\prime} \mathrm{W}$ and a nominal depth of $80 \mathrm{~m}$ ) as part of the HYDRO-CHANGES programme we initiated in 2002 (http://www.ciesm.org/marine/ programs/hydrochanges.htm). Recent conclusions and hypotheses about the MWs outflow (Millot, 2009; M09 hereafter), the interannual and seasonal variabilities of the AW inflow (Millot, 2007; M07) and the short-term variability of both the inflow and the outflow (Millot, 2008; M08) are summarized in the discussion. The observations presented here offer new objective constrains that hypotheses about the outflow heterogeneity must satisfy.

At point $\mathrm{M}$, the large amplitude of the semi-diurnal internal tide allows the CTD that was set there to monitor the inflow to also monitor part of the outflow (M07). The salinity $(S)$ of the inflow showed a huge increase in 2003-2007 $\left(\sim 0.05 \mathrm{yr}^{-1}\right)$ and a marked seasonal variability (range $\sim 0.4$, maximum in winter). A less regular but significant seasonal variability of its potential temperature $(\Theta)$ and density $(\sigma)$ was also observed with maxima in fall $(\Theta)$ and winter $(\sigma)$. This seasonal variability is mainly the result of air-sea interactions and mixing of AW with the MWs, both phenomena being intensified in winter (M07).

CTD sections performed across the strait about ten days apart show important short-term variability of the MWs outflow linked to the short-term spatiotemporal variability of the AW inflow (M08, M09). Indeed, the AW water mass is composed of the North Atlantic Central Water (NACW,

Published by Copernicus Publications on behalf of the European Geosciences Union. 

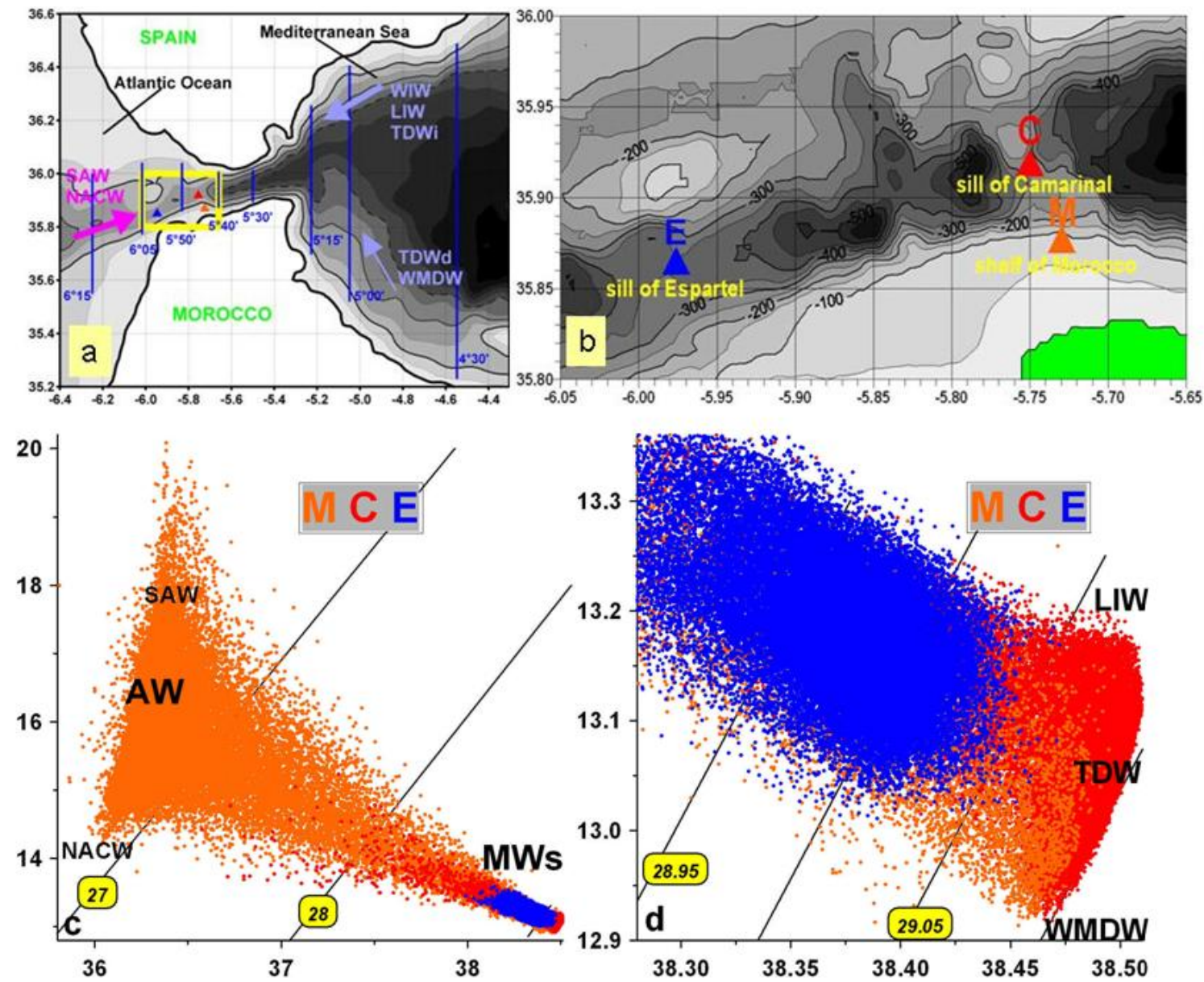

Fig. 1. (a, b) Locations of the CTDs moored at the sill of Camarinal (C, red triangle, $270 \mathrm{~m}$ ), on the shelf of Morocco (M, orange triangle, $80 \mathrm{~m}$ ) and at the sill of Espartel (E, blue triangle, $360 \mathrm{~m}$ ). The blue lines schematise the GIBEX sections (M09) and the waters acronyms are defined in the Discussion section. (c) $\Theta-S$ diagrams for the whole 2004-2008 period and over the whole data range at M, C and E. (d) $\Theta-S$ diagrams for the whole period and in the MWs ranges at M, C and E; WIW is not mentioned since it is roughly located near the AW-TDW mixing line, and is expected to outflow more to the north (M09).

$\Theta=13-14^{\circ} \mathrm{C}, S=35.5-36.0, \sigma=27.5-28.5 \mathrm{~kg} \mathrm{~m}^{-3}$ ) and a warmer, saltier and less dense water (Bray et al., 1995) called the Surface Atlantic Water (SAW, $\Theta=14-20^{\circ} \mathrm{C}, S=36.0$ $36.5, \sigma=26.5-27.5 \mathrm{~kg} \mathrm{~m}^{-3}$ ). Both can be identified, although mixed, at M all year long (Fig. 1c). M08 showed that the NACW proportion in the inflow (core at 100-200 m) displays a large local and/or temporal variability, and that the MWs mix mainly with NACW (SAW) when in large (low) volumes: the inflow composition (NACW vs. SAW) thus dramatically modifies the outflow characteristics. M09 showed that the MWs can outflow at $\mathrm{C}$ in a relatively unmixed condition and, identifying data supporting his case, argued that the MWs do not show a detectable seasonal variability upstream from the strait. Note that the relatively limited spreading of the MWs at M (Fig. 1d) does not allow for detection of a seasonal signal there. However, Garcia Lafuente et al. (2007, 2009; hereinafter GL07, GL09) detected a seasonal variability of the densest water samples observed every tidal cycle in the MWs outflow at the sill of Espartel (point $\mathrm{E}$, at $35^{\circ} 51.7^{\prime} \mathrm{N}-5^{\circ} 58.5^{\prime} \mathrm{W}$ and a nominal depth of $360 \mathrm{~m}$ ) that they ascribed to different proportions of LIW and WMDW in a relatively well mixed outflow. This could be linked to processes like the refilling of the western basin by newly formed WMDW, the strength of the western Alboran gyre, or the meteorological forcing, that are taking place within the sea. Whatever the case, Fig. 1d demonstrates that some MWs outflowing at $\mathrm{C}$ never outflow at M (i.e. LIW), and vice versa (i.e. WMDW), which account for the spatial heterogeneity of the outflow, at least near $5^{\circ} 45^{\prime} \mathrm{W}$.

The $\mathrm{C}$ and $\mathrm{M}$ CTDs are serviced by the Commission pour l'Exploration Scientifique de la mer Méditerranée (CIESM), the Centre d'Océanologie de Marseille (COM) and the Service Hydrographique et Océanographique de la Marine Royale du Maroc (SHOMAR) since January 2003, while the E CTD is serviced by the University of Malaga (UMA) since 30 September 2004 (day 1, d1). The three CTDs are operated 
within the HYDRO-CHANGES programme, the latter being supported by the Spanish-funded INGRES projects. This paper shows that the comparison of the CTD 1-h time series at $\mathrm{C}$ and $\mathrm{M}$ (serviced on $\mathrm{d} 898-9$ and d1489-90; subsequent time series are not calibrated yet) as well as at E (serviced on d1348-9) improves our understanding of both the seasonal and fortnightly variabilities of the MWs outflow.

\section{The data analysis}

Most of the time at $\mathrm{C}$ and always at $\mathrm{E}$, the time series show important semi-diurnal mixing of the MWs with AW (Fig. 2), and plotting median values over 25 -h running intervals provides valuable information (Fig. 3). Correlations between the $\Theta, S$ and $\sigma$ time series at $\mathrm{C}$ and $\mathrm{E}(\sim 21.2 \mathrm{~km}$ apart $)$ all peak at a $\sim 8$-h phase lag, which represents a realistic average flow speed of $\sim 0.7 \mathrm{~m} \mathrm{~s}^{-1}$; all analyses and figures are thus made with a modified $(-8 \mathrm{~h})$ E time.

The similarities of the $\Theta, S$ and $\sigma$ time series at $\mathrm{C}$ and $\mathrm{E}$ on a yearly time scale (Fig. 3a; $\mathrm{M}$ data are too sparse in the same ranges to provide usable information) indicate the existence of significant relationships between them, which is expected since streamlines roughly follow the steep bathymetry there (Fig. 1b). From C to E, the MWs outflow becomes warmer, fresher and less dense due to mixing with AW and entrainment of part of it, as already pointed out by GL07, while major variations at both $\mathrm{C}$ and $\mathrm{E}$ are larger and seemingly more similar for $\Theta$ than for $S$ and $\sigma$.

The $\Theta, S$ and $\sigma$ time series at $\mathrm{C}$ and $\mathrm{E}$ first show marked interannual variability. For instance, the MWs at both locations during the first winter (near d92) are warmer, fresher and less dense than during the remainder of the time series. It is also nearly impossible to discern a seasonal variability of these parameters, in particular at $\mathrm{C}$ where the MWs are less mixed with $\mathrm{AW}$ than at $\mathrm{E}$.

The green-rectangle portion of Fig. 3a, enlarged in Fig. 3c, shows that, as for long-term variations, the fortnightly ones at $\mathrm{C}$ are larger for $\Theta$ than for $S$ and $\sigma$. On the contrary, fortnightly variations at $\mathrm{E}$ are relatively large for all three parameters. Even though $\mathrm{E}$ is markedly deeper than $\mathrm{C}, \mathrm{MWs}$ at $\mathrm{E}$ display more variable and modified characteristics since they have been mixed with AW for a much longer time along their westward route.

\subsection{The seasonal variability}

Before detailing the $\mathrm{C}$ and $\mathrm{E}$ CTD time series, let us consider all the CTD vertical profiles available in the MEDATLAS data base (MEDAR group, 2002) in the vicinity of both $\mathrm{C}$ and $\mathrm{E}$ (Fig. 4a). While all profiles show AW-MWs mixing lines, most of the profiles near $\mathrm{C}$ show more or less pure MWs near the bottom. This statistical feature inferred from data of unknown quality and large spreading in time is nevertheless consistent with the high quality GIBEX data col-
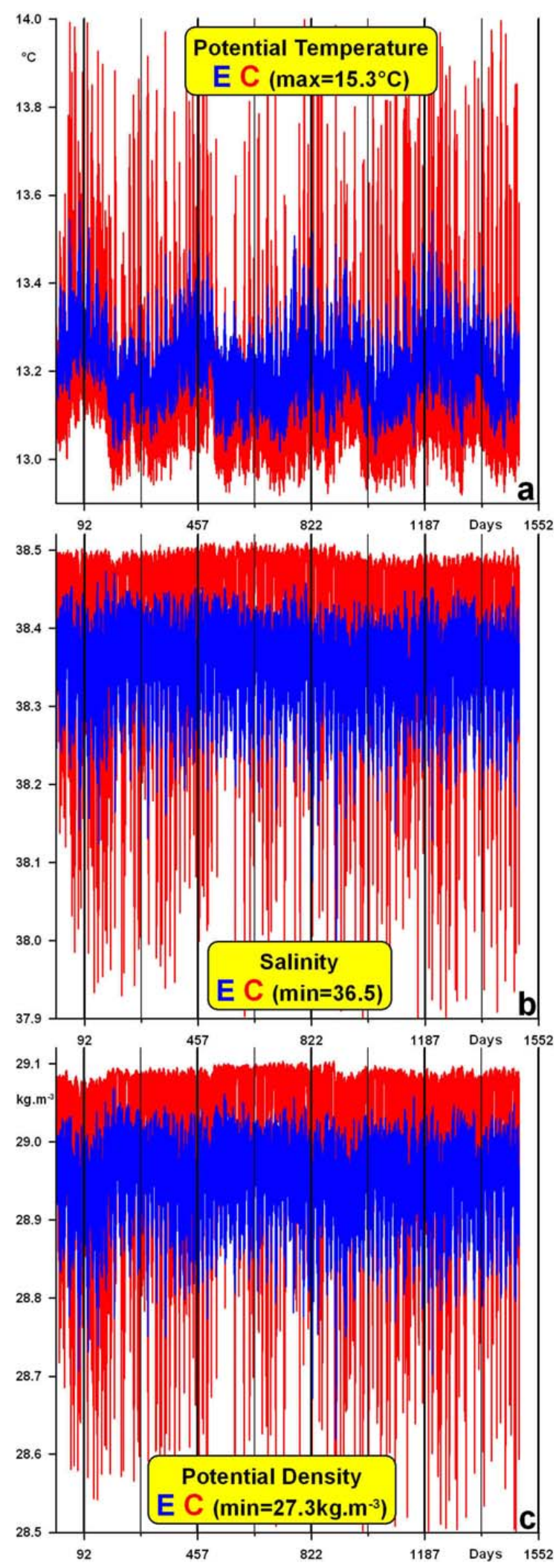

Fig. 2. Original time series of potential temperature (a), salinity (b) and potential density (c) at C (red) and E (blue) over specified ranges. 

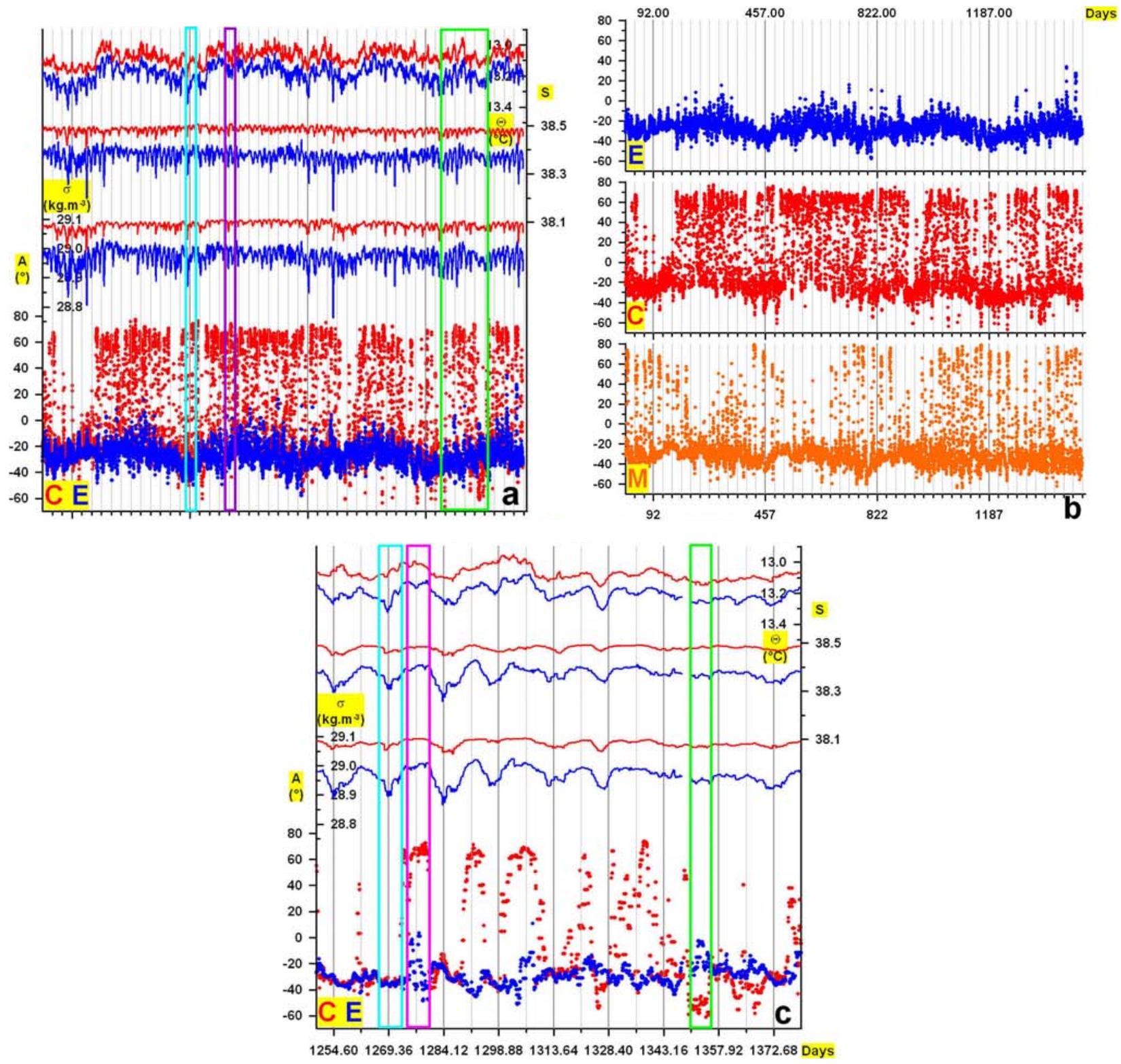

Fig. 3. (a) Time series (25-h median values) at both $\mathrm{C}$ (red) and E (blue) during the whole period (d1-d1490); on the time axis, major grid lines (dark grey on $\mathrm{d} 92, \ldots$ ) are on 1 January and minor grid lines (light grey) are one month apart. Coloured periods correspond to data plotted in Fig. 4b (cyan), Fig. 4c (magenta) and (c) (green). Ticks on the vertical axes indicate the overall ranges for the measured parameters $\Theta$ (descending axis), $S$ and $\sigma$, as well as the range of interest for the computed slope $A$ of the temporal mixing lines. (b) Computed slope $A$ of the temporal mixing lines at E, C and M. (c) As for (a) during the period specified in green in (a) (d1250-d1380); on the time axis, major grid lines (dark grey) indicate spring tide, minor grid lines (light grey) indicate neap tide, both being plotted 14.76 days apart. Coloured periods correspond to data plotted in Fig. 4d (cyan), Fig. 4e (magenta) and Fig. 4f (green).

lected in the deeper part of the strait at $5^{\circ} 40^{\prime} \mathrm{W}$ and $5^{\circ} 50^{\prime} \mathrm{W}$ (Fig. 1; Figs. 12-14 of M09), even if not taken exactly at the sills, where profiles are difficult to perform in a proper manner due to large currents and steep bathymetry. Linking the profiles with the time series can be roughly done by assuming that a given profile is displaced vertically by the semi-diurnal internal tide, i.e. ignoring the advection and spatiotemporal variability of the mixing. Such an assumption is supported by the following analysis and the similarities between the spatial and temporal $\Theta-S$ diagrams. Note that the MWs up to the late 1990s were significantly cooler and fresher than nowadays (Millot et al., 2006).

Our analysis is based on the mixing line computed from two successive records in a given time series (at $t$ and $t+1$ ), more specifically on the ratio $\left(\Theta_{t+1}-\Theta_{t}\right) /\left(S_{t+1}-S_{t}\right)=$ $\Delta \Theta / \Delta S$, the unit of which is ${ }^{\circ} \mathrm{C}$. Practically, and since we 

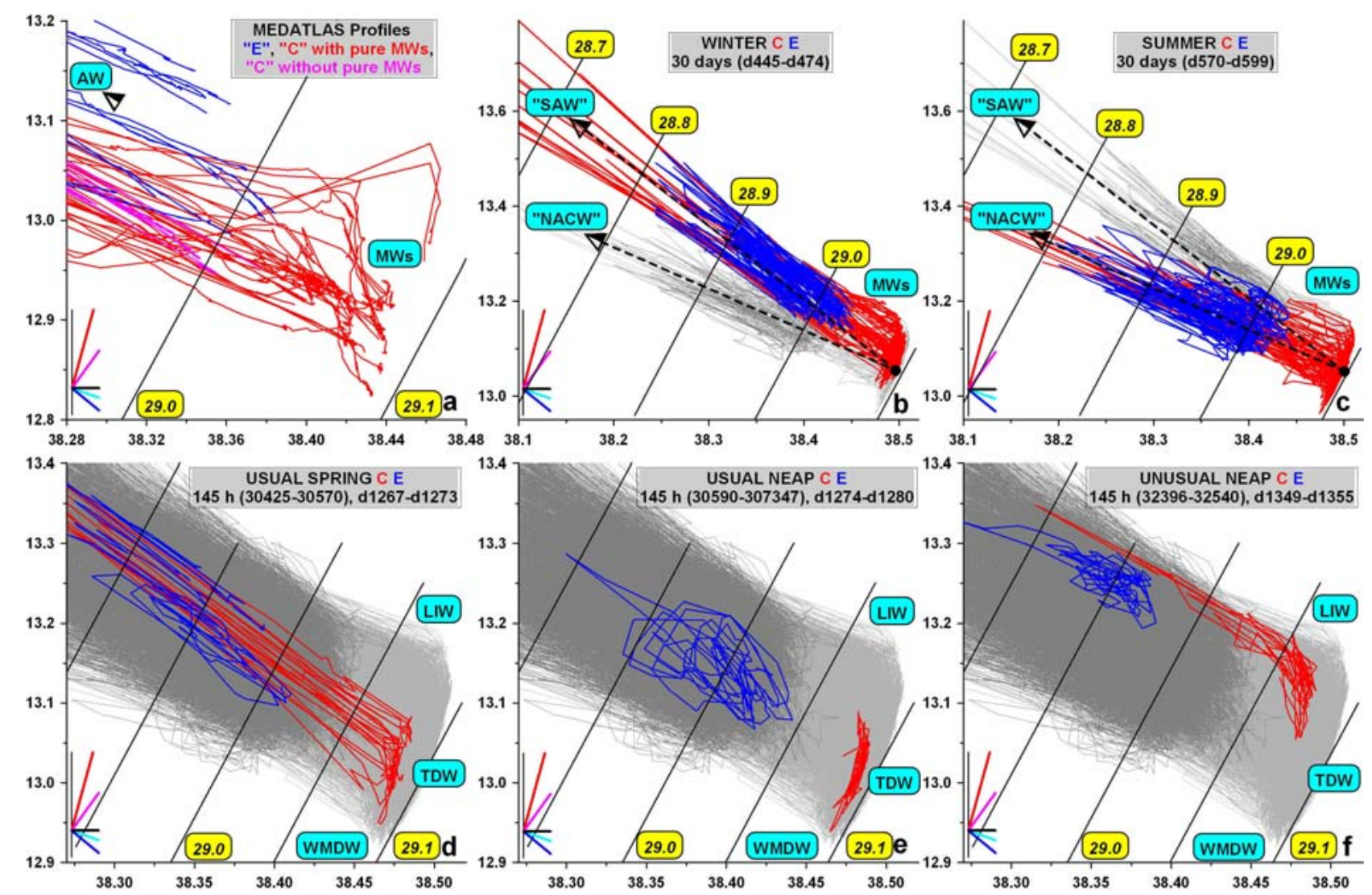

Fig. 4. $\Theta-S$ diagrams plotted with axes lengths allowing computed slopes $A$ (in ${ }^{\circ}$ ) to be compared to those of the segments coloured in red $\left(+75^{\circ}, \Delta \Theta / \Delta S \sim 7.5^{\circ} \mathrm{C}\right)$, magenta $\left(+55^{\circ}, 2.9^{\circ} \mathrm{C}\right)$, cyan $\left(-20^{\circ}, \sim-0.7^{\circ} \mathrm{C}\right)$ and blue $\left(-40^{\circ}, \sim-1.7^{\circ} \mathrm{C}\right)$ and plotted with respect to the black segment. In all figures, mixing lines at $\mathrm{C}(\mathrm{E})$ are in red (blue). (a) Diagrams from CTD profiles in the vicinity of $\mathrm{C}$ and $\mathrm{E}$, i.e. in rectangular areas centred on the moorings locations (latitude and longitude $\pm 1^{\prime}$ at $\mathrm{C}$ and $\pm 5^{\prime}$ at $\mathrm{E}$ ); at $\mathrm{C}$, some diagrams (magenta) do not contain evidence of any pure MWs. (b and c) Diagrams for the winter and summer/spring periods defined in cyan and magenta in Fig. 3a together with the corresponding mixing lines between the same MW (black dot) and some kinds of NACW and SAW; diagrams for the other season are plotted in light $(\mathrm{C})$ or dark (E) grey. (d, e and $\mathbf{f})$ Diagrams for the usual spring, usual neap and unusual neap periods defined in cyan, magenta and green in Fig. 3c; diagrams for the whole time series are plotted in light $(\mathrm{C})$ or dark $(\mathrm{E})$ grey.

display most $\Theta-S$ diagrams with axes having the same length for a $\Delta S$ range that is half the $\Delta \Theta$ one in classical $\Theta\left({ }^{\circ} \mathrm{C}\right)$ and $S$ units, we consider the related slope $A=\operatorname{atan}(\Delta \Theta / \Delta S / 2)$ in degrees $\left({ }^{\circ}\right)$ that can thus be easily interpreted. As already suggested by the $\Theta-S$ diagrams inferred from the CTD profiles (Fig. 4a), and as demonstrated thereafter by the $\Theta-S$ diagrams inferred from the time series, most of the slopes of the mixing lines between AW and the MWs (Fig. 3a) are in the range $-20^{\circ}$ to $-40^{\circ}$ while those between the MWs (i.e. when unmixed with $\mathrm{AW}$ ) are in the range $+55^{\circ}$ to $+75^{\circ}$. All 25-h median values of the slope at E, C and M display very clear and significant characteristics (Fig. 3b).

Positive slopes are observed at $\mathrm{C}$ (concentrated in the range $55^{\circ}$ to $75^{\circ}$ ) and $\mathrm{M}$, not at $\mathrm{E}$. At $\mathrm{C}$, these slopes indicate mixing between pure MWs (involving no AW at all) and are consistent with the fact that pure MWs can be found in significant amounts only there and at neither M (M09) nor E (GL07). At M, these slopes indicate mixing between
NACW and SAW (data are too scarce in the MWs ranges), hence some kind of relatively pure AW (involving no MWs at all) associated either with the seasonal mixed layer or with wintertime mixing. Accordingly, positive slopes occur nearly all year long, except in spring when the AW is continuously stratified so that mixing necessarily involves some MWs (most of the slopes being negative). In agreement with previous analyses (Millot et al., 2006; M09) the outflow at $\mathrm{C}$ and $\mathrm{M}$ displays large interannual to long-term variability. For instance, MWs at $\mathrm{C}$ were much more mixed with AW during the first winter than during the following ones (no A values at $\mathrm{C}$ in the range $55^{\circ}$ to $75^{\circ}$ near d92). Additionally, and whichever measured or computed parameter is considered, pure MWs (at C) do not display noticeable seasonal variability. 
On the contrary, nearly all E slopes are negative and most of them concentrate in the $-20^{\circ}$ to $-40^{\circ}$ range; in that range, a large amount of $\mathrm{C}$ slopes are very similar (Fig. 3b, masked in Fig. 3a). Interestingly, these $\mathrm{C}$ and $\mathrm{E}$ slopes that are indicative of AW-MWs mixing display a marked seasonal variability with, schematically, larger slopes (near $-40^{\circ}$ ) in winter and lower slopes (near $-20^{\circ}$ ) in summer. Corresponding $\Theta-$ $S$ diagrams plotted over one-month periods (to display a sufficiently large number of data) are shown in Fig. $4 \mathrm{~b}$ for winter and in Fig. 4c for summer, or more precisely late spring (to find a nearby period during which the MWs were roughly similar). They indicate that (a) mixed MWs at both $\mathrm{C}$ and $\mathrm{E}$ display a marked seasonal variability; (b) MWs at E generally result from the mixing with AW of the MWs encountered at $\mathrm{C}$; (c) MWs mix with two kinds of AW; (d) representative mixing lines (dashed) intersect (black dot) in the MWs' range. Therefore, any seasonal signal about the sea functioning (excluding the strait) will be more easily inferred either from only the pure MWs at C (neither expected nor found yet by e.g. M09) or from the MWs upstream from C (convenient data not available yet).

The negative slopes at $\mathrm{M}$ (Fig. 3b) display a seasonality that is very similar to those at both $\mathrm{C}$ and $\mathrm{E}$; this accounts for AW-MWs mixing processes occurring similarly over the whole strait. Very interestingly, slopes at $\mathrm{M}$ are more negative than at both $\mathrm{C}$ and $\mathrm{E}$ during the whole four-year period, especially during the last two years. Note (Fig. 1c) that, even though temporal $\Theta-S$ diagrams at $\mathrm{C}$ and $\mathrm{E}$ do not show evidence of any relatively unmixed AW, the temporal diagram at $\mathrm{M}$ and the spatial diagrams in the central part of the strait (e.g. Fig. 2 of M08, Fig. 16b of M09) indicate that the lowest (largest) slopes correspond to mixing of the MWs with some kind of NACW (SAW). The fact that NACW is deeper than SAW explains why the MWs on the shelf mix more with SAW than the deep MWs do, and why the less mixed AW at $\mathrm{C}$ is NACW (Fig. 1c). According to the GIBEX data (M08, M09), NACW can be either totally absent or concentrated near some specific latitude within the strait on a time scale of a few days. It can thus be concluded that the mixing of each of the MWs with AW occurs on time scales ranging from days to seasons (in the long-term as well) and is dependent on both the spatial distributions of NACW and SAW and on their cross-strait location.

Additionally, the GIBEX data (auxiliary Figs. 1, 2 and 3 of M08) show noticeable seasonal variability of the AW stratification down to relatively large depths (100-200 m) consistent with the seasonal variability of the $\mathrm{M}$ positive slopes (Fig. 3b). Therefore, the whole outflow's characteristics, i.e. not only in its upper part but also down to the sills' depths, are dependent on the seasonality of the AW composition and stratification. It can be that, during summer, the seasonal pycnocline prevents AW from within the mixed layer (i.e. SAW) from mixing with the MWs that consequently mix with relatively pure NACW (when present), i.e. with a relatively cool and fresh type of AW. During winter, the seasonal mixed layer disappears and NACW (when present) mixes with SAW so that, in any case, the MWs mix with a type of AW warmer and saltier than NACW.

\subsection{The fortnightly variability}

During a usual spring-tide period (Fig. 4d), AW-MWs mixing lines have slopes of $-35^{\circ}$ to $-40^{\circ}$ at both $\mathrm{E}$ and $\mathrm{C}$, and the MWs at $\mathrm{E}$ are those encountered at $\mathrm{C}$ where they can outflow relatively unmixed with $\mathrm{AW}$ (slopes of $\sim 75^{\circ}$, mainly TDW).

During an usual neap-tide period (Fig. 4e), C slopes are in the range $55^{\circ}$ to $75^{\circ}$ and even more (up to $\sim 90^{\circ}$ ), showing evidence of the same MW (mainly TDW) as during the previous spring-tide period but that now never mixes with AW. At E, the MWs are much less mixed with AW than during spring-tide periods, and the E slopes indicative of mixing between the MWs tend towards the C ones (Fig. 3c).

During an unusual neap-tide period (Fig. 4f), mainly LIW but also TDW are outflowing at $\mathrm{C}$ so that slopes associated with the mixing of these MWs become larger and even negative $\left(\sim-50^{\circ}\right.$, see $\Theta-S$ diagrams in M09), especially when considering median values (Fig. 3c). Some of the AW-MWs mixing lines at $\mathrm{C}$ do not correspond to the MWs encountered at $\mathrm{E}$. This fact, along with the differences between the MWs at $\mathrm{C}$ and $\mathrm{M}$ (Fig. 1d), support the MWs outflow heterogeneity, which is not usually evident from data collected at $\mathrm{C}$ and $\mathrm{E}$ that are more or less along the same streamlines.

\section{Discussion}

Previous papers about Gibraltar never envisaged several characteristics of both the Mediterranean inflow and outflow that could have been anticipated from an understanding of the circulation in the Mediterranean Sea, but have only recently been supported by direct evidence (Millot et al., 2006; M07, M08, M09).

In the westernmost part of the sea, intermediate MWs (the Winter Intermediate Water, WIW, the Levantine Intermediate Water, LIW, and the upper part of the Tyrrhenian Dense Water, TDWi) clearly circulate alongslope counterclockwise due to the Coriolis effect, thus entering the strait along its northern slope one above the other (M09). There, the deep MWs (TDWd and WMDW, the Western Mediterranean Deep Water) circulate only sluggishly (Bryden and Stommel, 1982). The following hypotheses (M09) about more or less accepted features have yet to be validated. In this part of the sea, the deep MWs are mainly pushed by the intermediate MWs off the southern slope where they are in direct contact with AW and thus mix noticeably with it. Since the bathymetric section becomes constricted when entering the strait, intermediate MWs accelerate so that their interface with the deep MWs tilts up southward, hence easing the lifting of the latter. Schematically, the MWs that are superimposed in the sea 
thus come to be juxtaposed in the strait, the denser outflowing along the slope off Morocco and each of them mixing directly with AW (an update of the cartoon proposed by Millot et al., 2006 will be proposed soon). Since the bathymetric section widens when leaving the strait, the mixed MWs decelerate and their interface first flattens. Then, each mixed MW progressively cascades down to its specific level of equilibrium before flowing independently from the others along the Iberian slope. In the ocean, the outflow is thus structured in a number of veins, each of them being mainly dependent on the composition of the outflow in terms of MWs when entering the strait and on its interactions with the inflow within the strait.

With AW being composed of NACW (relatively cool, fresh and dense) and SAW (relatively warm, salty and light), we have illustrated how the variability of the NACW can induce, on time scales of a few days and under the action of tidal mixing, a corresponding variability of the characteristics of the outflow down to the deeper part of the strait (M08). We also presented evidence of a marked seasonal variability of the inflow at $\mathrm{M}$ that we linked with air-sea interactions and mixing with the outflow there, both processes being intensified in winter (M07). These results are consistent with those inferred from the comparison that has been performed here between the $\mathrm{C}, \mathrm{E}$ and $\mathrm{M}$ time series.

We show that the seasonal variability of the inflow induces a seasonal variability of the outflow in the deeper part of the strait as well as on the Moroccan shelf. The MWs mix with a type of AW that is cooler (warmer) and fresher (saltier) in summer (winter), with shallower MWs preferentially mixing with lighter AW components. This can be due either to the seasonal stratification of AW that would decrease (increase) in summer (winter) the mixing between SAW and NACW, both assumed to occur in relatively stable proportions on seasonal and longer time scales, or to a NACW volume that would be larger in summer for some unknown reason.

The paper also illustrates the fortnightly variability that is induced by tides. Even though such variability was partially known (e.g. Vargas et al., 2006), comparison of time series collected at $\mathrm{C}$ and $\mathrm{E}$ provide additional information. Even during neap-tide periods when the outflow can remain totally unmixed with the inflow over several days at $C$, it is markedly mixed when arriving at $\mathrm{E}$, further downstream.

Therefore, a pure MW approaching the deeper part of the strait (identified by the black dot in Fig. 4b, c) leads, from winter to summer, to a very different MW even at $\mathrm{C}$ during spring-tide periods, as well as at $\mathrm{E}$ and further downstream all year long. Since mixing of the MWs with AW is necessarily intensified at shallower depths, i.e. all across the Camarinal section for instance, other parts of the outflow that have not been sampled yet encounter similar, and probably larger, seasonal and fortnightly variabilities.

Consequently, looking for a seasonal variability of the outflow that could be linked with the functioning of the sea itself will be more readily achieved at $\mathrm{C}$, only considering the
MWs unmixed with AW, or further upstream. Whatever the case, the tides in the strait strongly mix the outflow with an inflow that is highly variable on time scales ranging from days to seasons and years. Characteristics of the outflow in the ocean are thus almost unpredictable, at least with accuracies such as those implied up to now.

Acknowledgements. This paper is a contribution to the International HydroChanges CIESM Program. C. M. warmly thanks the COM and the CIESM for their technical and financial support as well as the SHOMAR for their very efficient logistics. We thank Antonio Sanchez-Roman and Jean-Luc Fuda for having provided C. M. with bathymetric data in a specific format. J. G. L. is grateful to the Spanish Ministry of Science and Technology for the financial support of INGRES projects (CTM2006-02326, CTM-2009-5810-E and CTM2010-21229). We also thank both Dick Marx and the Editor for improving the English.

Edited by: M. Hecht

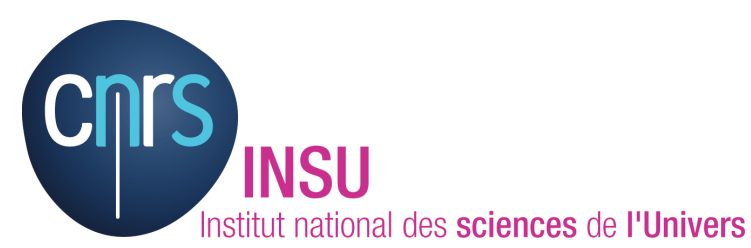

The publication of this article is financed by CNRS-INSU.

\section{References}

Bray, N. A., Ochoa, J., and Kinder, T. H.: The role of the interface in exchange through the Strait of Gibraltar, J. Geophys. Res., 100, C6, 10755-10776, 1995.

Bryden, H. L. and Stommel, H. H.: Origin of the Mediterranean outflow, J. Mar. Res., Suppl. 40, 55-71, 1982.

García-Lafuente, J., Sánchez-Román, A., Díaz del Río, G., Sannino, G., and Sánchez-Garrido, J. C.: Recent observations of seasonal variability of the Mediterranean outflow in the Strait of Gibraltar, J. Geophys. Res., 112, C10005, doi:10.1029/2006JC003992, 2007.

García-Lafuente, J., Delgado, J., Sánchez-Román, A., Soto, J., Carracedo, L., and Díaz del Río, G.: Interanual variability of the Mediterranean outflow observed in Espartel sill, western strait of Gibraltar, J. Geophys. Res., 114, C10018, doi:10.1029/2009JC005496, 2009.

MEDAR Group: MEDATLAS/2002 database. Mediterranean and Black Sea database of temperature salinity and bio-chemical parameters, Climatological Atlas, IFREMER Edition (4 CDroms), 2002.

Millot, C.: Interannual salinification of the Mediterranean inflow, Geophys. Res. Lett., 34, L21609, doi:10.1029/2007GL031179, 2007.

Millot, C.: Short-term variability of the Mediterranean in- and out-flows, Geophys. Res. Lett., 35, L15603, doi:10.1029/2008GL033762, 2008. 
Millot, C.: Another description of the Mediterranean Sea outflow, Prog. Oceanogr., 82(2), 101-124, doi:10.1016/j.pocean.2009.04.016, 2009.

Millot, C., Candela, J., Fuda, J.-L., and Tber, Y.: Large warming and salinification of the Mediterranean outflow due to changes in its composition, Deep-Sea Res., 53/4, 656-666, doi:10.1016/j.dsr.2005.12.017, 2006.
Vargas, J. M., García-Lafuente, J., Candela, J., and Sánchez Román, A.: Fortnightly and monthly variability of the exchange through the Strait of Gibraltar, Prog. Oceanogr., 70, 466-485, doi:10.1016/j.pocean.2006.07.001, 2006. 